\title{
Calculation of Control Rods Reactivity Worth of RSG-GAS First Core Using Deterministic and Monte Carlo Methods
}

\author{
T. Surbakti ${ }^{1^{\star}}$, S. Pinem ${ }^{1}$, T.M. Sembiring ${ }^{2}$, A. Hamzah ${ }^{1}$ and K. Nabeshima ${ }^{3}$ \\ ${ }^{1}$ Center for Nuclear Reactor Technology and Safety, National Nuclear Energy Agency, \\ Kawasan Puspiptek Serpong, Tangerang Selatan 15310, Indonesia \\ ${ }^{2}$ Center for Assessment of Nuclear Energy System, National Nuclear Energy Agency, \\ Jl. Kuningan Barat, Mampang Prapatan, Jakarta 12710, Indonesia \\ ${ }^{3}$ Fast Reactor Computer Engineering Department, Ibaraki, JAEA, Japan
}

\section{ARTICLE INFO}

\section{Article history:}

Received 10 January 2018

Received in revised form 2 November 2018 Accepted 5 November 2018

\section{Keywords:}

Control rod

Research reactor

MCNP6 code

Batan-3DIFF code,

RSG-GAS first core

\begin{abstract}
A B S T R A C T
The control rod worth is a key parameter for the research reactor operation and utilization. Control rod worth computation is a challenge for the fully-deterministic and Monte Carlo calculations, including the few-group cross section generation, and the core analysis. The safe and reliable utilization of research reactor demands the possible accurate information of control rod worth because they are used to compensate the excess reactivity for safe reactor operation and its controlled shut down. The criticality positions of the control rods change with time due to buildup of fission products during the reactor operation. It is therefore important to determine the reactivity worth of control rods. The aim of this article is to obtain reliable control rod worth of the first core of RSG-GAS as a verification and validation result. For this purpose, deterministic and Monte Carlo models of the reactor core were developed and confirmed by the experimental results of excess reactivity, shutdown margin, and combined control rod reactivity worth using the combination of WIMSD-5B and Batan-3DIFF computer codes. WIMSD-5B is a neutron transport theory-based lattice cell modeling code that is used for the generation of group constants for different regions of the reactor core. These are provided as input to the diffusion theory based Batan-3DIFF code which performs the global core calculations for the reactor system. For the Monte Carlo model, to estimate the reactivity worth of control rods, the MCNP6 code is used. The result of this analysis showed that for the integral control rod worth a good agreement was found between experimental data and Monte Carlo simulation results but up to $5 \%$ difference occurred between experimental results and diffusion result.
\end{abstract}

(C) 2019 Atom Indonesia. All rights reserved

\section{INTRODUCTION}

Control rod reactivity worth calculation is crucial for a nuclear reactor. One of the main purposes of control rods is for scramming the reactor in case of an emergency. Control rods are also used for providing positive reactivity to the core for reactor startup in the case of xenon peaking in the post-shutdown condition [1]. Thus, knowing the amount of negative reactivity of a particular control rod becomes important. The location of the

*Corresponding author.

E-mail address: tukiran@batan.go.id

DOI: https://doi.org/10.17146/aij.2019.810 control rod in the nuclear reactor core determines the reactivity worth of the rod since neutron flux is the function of position in the core. A control absorber placed in high neutron flux has high reactivity worth as compared to when it is placed at a location having lower flux. Control rod worth can also be measured experimentally using, for instance, the method of the positive period. However, for a nuclear reactor design or at the time when new reactor core is assembled, the reactivity worth of all control rods are calculated using software packages that can model the reactor core and control rods [2]. This work focuses on the estimation of reactivity worth of control rods for the first core of the 
RSG-GAS reactor. The RSG-GAS reactor is a water-moderated pool-type reactor designed for radioisotope production and testing many types of objects in the steady-state modes of operation [3]. One of the distinguishing features of the RSG-GAS core is the large irradiation facility $(4 \mathrm{~cm} \times 8.1 \mathrm{~cm} \mathrm{x}$ $7.71 \mathrm{~cm})$ in central irradiation position. However, sufficient calculation efforts using a sophisticated method such as Monte Carlo method have not been conducted. In this report, deterministic and Monte Carlo calculation results for control rods worth of the RSG-GAS first core will be presented and compared with the experimental data. The purpose of this research is to reliably obtain the control rod worth of the first core of RSG-GAS as a verification and validation result. The first core was chosen for two reasons, namely first, the completeness of the experimental data, and second, the fuel elements, absorber and beryllium reflectors were still fresh and therefore the uncertainties raised from the fuel burnup and absorber depletion calculations, and from the calculation of lithium poisoning in the beryllium reflectors can be eliminated. The continuous-energy Monte Carlo code, MCNP6 [4], was used for the entire calculations. In the present work, as the nuclear data libraries for the code, the Evaluated Nuclear Data Library, ENDFVII.1 [5] is used to check their accuracy by comparing to the experimental data. The Monte Carlo method has been selected for the present work since it is the most accurate method for control rod reactivity worth calculations. The exact geometry, dimension and composition of the reactor details can be modeled in 3-D Monte Carlo method, and the neutron transport can be simulated without any approximation. Many researchers have performed researches for control rod worth estimation using computer code [6-9]. However, this research used the computer codes implementation of Monte Carlo and diffusion methods. They have to consider the type of neutron cross section data which will be used in the simulation. In the early application of Monte Carlo code for criticality calculations the group approximation with many energy groups was commonly used since the computer memory and computational capacity were then limited. In this case the continuous neutron energy is approximated by many discrete energy groups. With the rapid development of computer technology, the limitation can be relaxed significantly. The most advanced Monte Carlo codes, such as MCNP6 code that was used in the present work, use the energy-continuous cross section data which removes the approximation applied in the neutron energy variable. On top of that, in order to save computational time, the code has been vectorized by taking the advantage of the parallel processing technology presently available. The results will be compared to the deterministic method using the Batan-3DIFF code and also with the experimental data.

BATAN's standard neutron diffusion code, Batan-3DIFF [3] code, has been developed in BATAN for neutronic design and safety analysis, especially design and analysis of research reactors. Those codes solve the three-dimensional multigroup neutron diffusion problems, respectively. The code has been continuously upgraded to expand its capability to include, for instance, the calculation of kinetic parameters, fast calculation of reactivity changes based on the perturbation theory, and solving the fixed source problem. The code has been validated through two activities, namely, first, modeling the RSG-GAS core, and second, modeling the Kyoto University Critical Assembly (KUCA). In the first validation activity, Batan-2DIFF code was validated on the IAEA benchmark core (static calculation). The accuracy on the code has been investigated for all aspects of neutronic design such as criticality, various types of power peaking factor, isothermal feedback reactivity coefficients, and fuel element worth. However, all calculations involved were modeled in 2-D reactor geometry. Furthermore, two options for treating strong absorber, i.e., blackness coefficient and effective diffusion parameter, have also been successfully implemented by Center for Multipurpose Reactor, National Atomic Energy Agency, in Batan-2DIFF and verified through the benchmark calculations. In this case, the fully-inserted and fully-withdrawn control rod configurations can be treated in 2-D reactor geometry and solved with Batan-2DIFF without sacrificing the accuracy. In the second validation activity, Batan-3DIFF code was validated on the Kyoto University Critical Assembly (KUCA) for the effective multiplication factor (eigenvalue problem) where a 3-D model can be fully adopted. However, in the validation work, no absorber was involved since all of the assemblies were almost critical. In the present validation work, the above mentioned work is extended to calculate the fullyand partially-inserted control rod configuration in 3-D reactor geometry. The IAEA benchmark core was selected as the benchmark object in this paper due to two reasons. The first reason is the availability of all parameters concerning the partially-inserted control rod parameters, such as the rod worth, the change of the power peaking factor and the change of the axial power density profile and shift. The secondl reason is that the previous benchmark calculations have also been done against the IAEA benchmark core. This core is an MTR core and its fuel element configuration is 
considerably close to the one of the Multipurpose research reactor RSG-GAS.

\section{THEORY}

\section{RSG-GAS first core}

The Indonesian multipurpose research reactor, RSG-GAS, is a beryllium-reflected, lightwater-moderated and -cooled, $30 \mathrm{MWth}$ (max.) tank in pool type reactor. The first criticality of the reactor was achieved on July 29, 1987 [9]. The core configuration of the RSG-GAS for the first criticality is shown in Fig. 1 and the first core configuration of RSG-GAS is shown in Fig. 2.

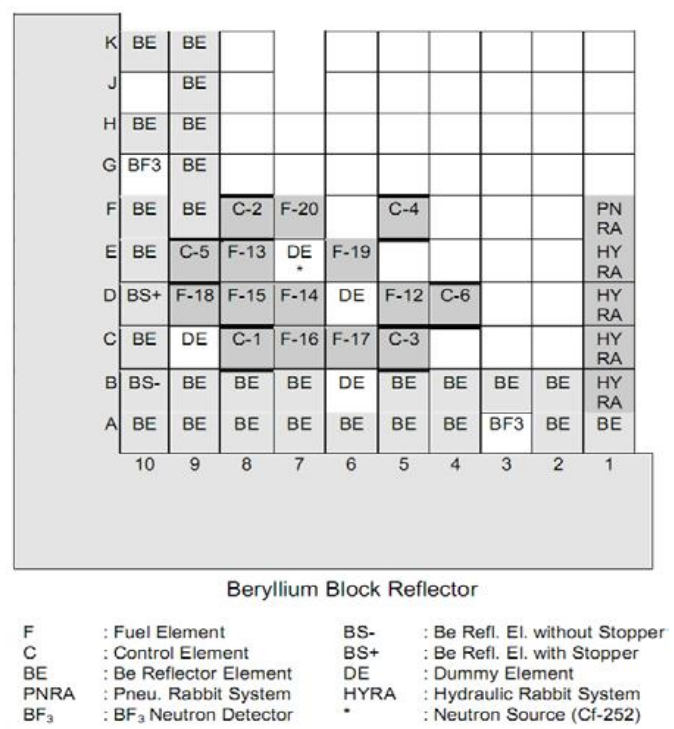

Fig. 1. First criticality core configuration of RSG-GAS first core[13].

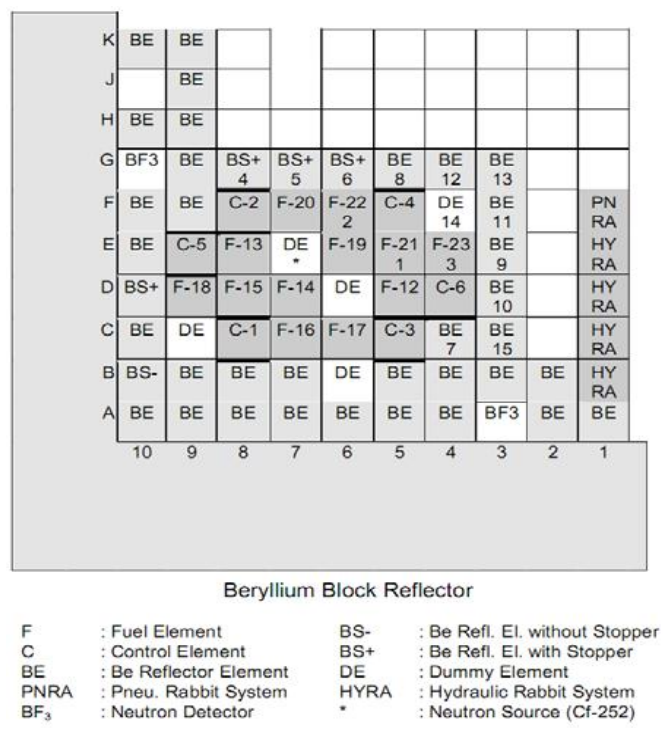

Fig. 2. Full core configuration of RSG-GAS first core [13].
RSG-GAS has five transition cores (smaller cores) before a full core configuration can be achieved in the sixth core. The full core configuration is commonly called the typical working core (TWC) and consists of forty standard fuel elements and eight control fuel elements. In the present benchmark analyses, several criticality configurations were selected, especially from the un-burnt first core configurations. The reactor main data is shown in Table 1.

Table 1. Main data of RSG-GAS first core[12].

\begin{tabular}{ll}
\hline Parameter & Size /material/type \\
\hline Reactor type & Tank in open pool \\
Fuel element & LEU oxide MTR \\
Moderator/coolant & $\mathrm{H}_{2} \mathrm{O}$ \\
Reflector & $\mathrm{Be}$ and $\mathrm{H}_{2} \mathrm{O}$ \\
Power at first core (MWt) & 10 \\
No. of fuel elements & 12 \\
No. of control elements & 6 \\
No. of fork type absorber s & 6 \\
Fuel/control element & $77.1 \times 8.1 \times 60$ \\
Fuel plate thickness (mm) & 1.3 \\
Coolant channel width $(\mathrm{mm})$ & 2.55 \\
No. of plates per fuel element & 21 \\
No. of plates per control element & 15 \\
Fuel plate cladding material & $\mathrm{AlMg} 2$ \\
Fuel plate cladding thickness $(\mathrm{mm})$ & 0.38 \\
Fuel meat dimension $(\mathrm{mm})$ & $0.54 \times 62.75 \times 600$ \\
Fuel meat material & $\mathrm{U}_{3} \mathrm{O}_{8} \mathrm{Al}$ \\
${ }^{235} \mathrm{U}$ enrichment $(w / o)$ & 19.75 \\
Uranium density in meat $\left(\mathrm{g} / \mathrm{cm}^{3}\right)$ & 2.96 \\
${ }^{235} \mathrm{U}$ loading per fuel element $(\mathrm{g})$ & 250 \\
${ }^{235} \mathrm{U}$ loading per control element $(\mathrm{g})$ & 178.6 \\
Absorber meat material & $\mathrm{Ag}-\mathrm{In}-\mathrm{Cd}$ \\
Absorber thickness (mm) & 3.38 \\
Ansorber cladding material & $\mathrm{SS}-321$ \\
Absorber cladding thickness & 0.85 \\
\hline
\end{tabular}

Fuel elements used for RSG-GAS are of the material testing reactor, i.e., plate-type fuel elements, and one fuel element consists of 21 fuel plates assembled by two side plates. The cross-sectional view of RSG-GAS standard fuel element is shown in Fig. 3.

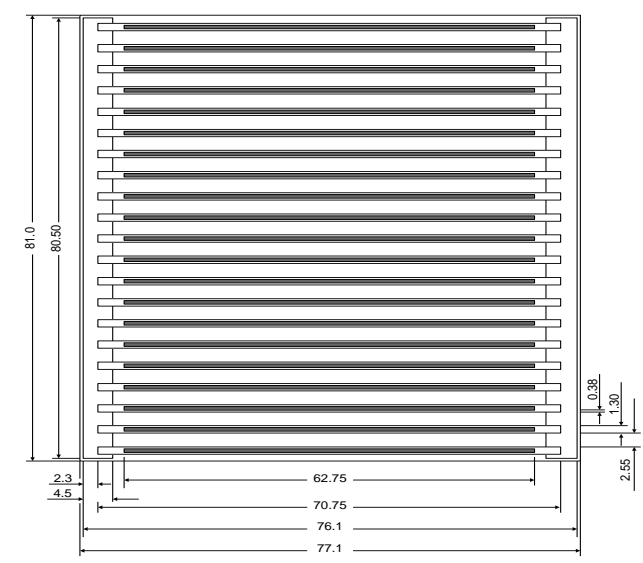

Fig. 3. Standard fuel element of RSG-GAS Reactor (dimensions in $\mathrm{mm}$ ) [17]. 
One fuel plate consists of $19.75 \%$ enriched uranium oxide meat (with uranium density of $2.96 \mathrm{~g} \mathrm{U} / \mathrm{cc}$ ) dispersed in the aluminum matrix, with aluminum cladding on both sides of the meat. The active length of the fuel element (or the meat height) is $60 \mathrm{~cm}$. The nominal ${ }^{235} \mathrm{U}$ loading per standard fuel element is $250 \mathrm{~g}$ [10]. Control fuel elements, shown in Fig. 5, with identical outer dimension consist of 15 fuel plates; that is, three fuel plates at both outer sides of the fuel elements are removed to provide space for absorber blades, and therefore the nominal ${ }^{235} \mathrm{U}$ loading for a control fuel element reduces to $178.57 \mathrm{~g}$. At both sides of the control fuel element, two absorber guide plates (aluminum) are installed. A fork-type control rod $(0.38-\mathrm{cm}$ thick Ag-In-Cd absorber meat with SS-321 cladding) can be inserted into or withdrawn from the control fuel element. The core configurations will be described in the next sub-section.

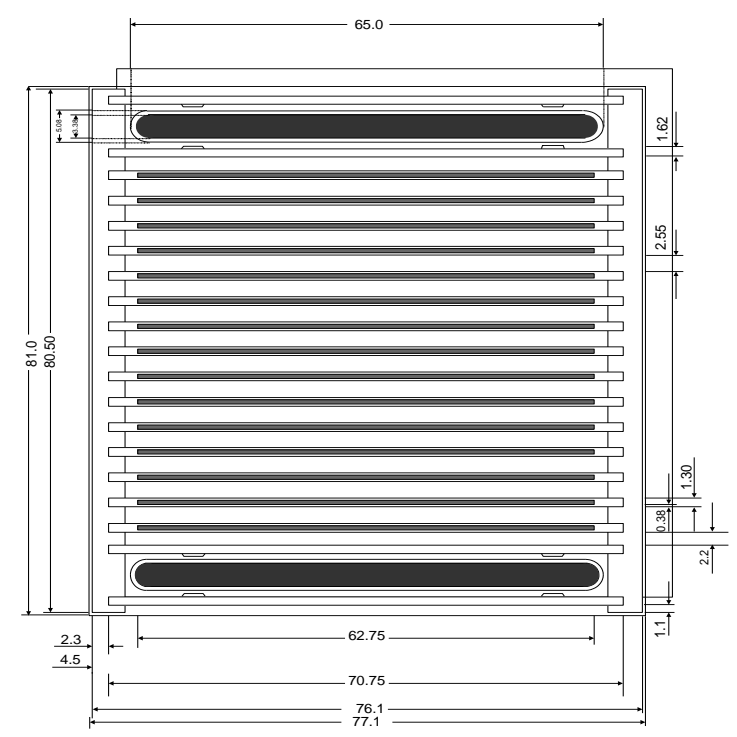

Fig. 5. Control rod fuel element (dimensions in mm) [19].

First, estimation of the number of standard and control fuel elements required for the first criticality was conducted. It was expected that the first criticality (with small excess reactivity) would be achieved with six control fuel elements and nine standard fuel elements while all control rods were withdrawn. Second, six control fuel elements were loaded into the core with the absorber plates were all fully inserted. A ${ }^{252} \mathrm{Cf}$ neutron source was inserted into the E-7 grid position to initiate fission chain reactions, and then standard fuel elements were loaded step by step [11]. After the first criticality, loading of fuel elements and reflector elements were conducted to achieve a full core configuration with sufficient excess reactivity for one cycle. After the full configuration of the first core was achieved, the measurement excess reactivity was done. This excess reactivity was converted to effective multiplication factor. The data for first core configuration of RSG-GAS is shown in Table 1.

Table 1. Main data of RSG-GAS first core[12].

\begin{tabular}{ll}
\hline Parameter & Size /material/type \\
\hline Reactor type & Tank in open pool \\
Fuel element & LEU oxide MTR \\
Moderator/coolant & $\mathrm{H}_{2} \mathrm{O}$ \\
Reflector & $\mathrm{Be}$ and $\mathrm{H}_{2} \mathrm{O}$ \\
Power at first core $(\mathrm{MWt})$ & 10 \\
No. of fuel elements & 12 \\
No. of control elements & 6 \\
No. of fork type absorber s & 6 \\
Fuel/control element & $77.1 \times 8.1 \times 60$ \\
Fuel plate thickness (mm) & 1.3 \\
Coolant channel width (mm) & 2.55 \\
No. of plates per fuel element & 21 \\
No. of plates per control element & 15 \\
Fuel plate cladding material & $\mathrm{AlMg} 2$ \\
Fuel plate cladding thickness $(\mathrm{mm})$ & 0.38 \\
Fuel meat dimension (mm) & $0.54 \times 62.75 \times 600$ \\
Fuel meat material & $\mathrm{U}_{3} \mathrm{O}_{8} \mathrm{Al}$ \\
${ }^{235} \mathrm{U}$ enrichment (w/o) & 19.75 \\
Uranium density in meat $\left(\mathrm{g} / \mathrm{cm}^{3}\right)$ & 2.96 \\
${ }^{235} \mathrm{U}$ loading per fuel element $(\mathrm{g})$ & 250 \\
${ }^{235} \mathrm{U}$ loading per control element $(\mathrm{g})$ & 178.6 \\
Absorber meat material & $\mathrm{Ag}-\mathrm{In}-\mathrm{Cd}$ \\
Absorber thickness (mm) & 3.38 \\
Ansorber cladding material & $\mathrm{SS}-321$ \\
Absorber cladding thickness & 0.85 \\
\hline
\end{tabular}

\section{METHODOLOGY}

For performing neutron calculation in the reactor core, reactor simulation is necessary. In this study, two steps have been used for reactor simulation. The first step is cell calculation that simulates fuel assemblies in reactor core and the second step is core calculation that simulates reactor core. In the first step, cell calculations, macroscopic cross-sections for all parts of core, such as fuel assemblies and reflectors, are calculated and used in the next step, that is, the core calculation, which performs the calculation of neutronic parameters. Details of these two steps are as follows.

\section{Fuel cell calculation}

Few-group cross-sections of the standard fuel elements (Fig. 3) are prepared by the 1-D model of a quarter of the fuel element (Fig. 4) averaged by SN method with multi plate option in the WIMSD-5B code [14], so that the 4-group effective cross-section for one standard fuel element is obtained with this calculation. 


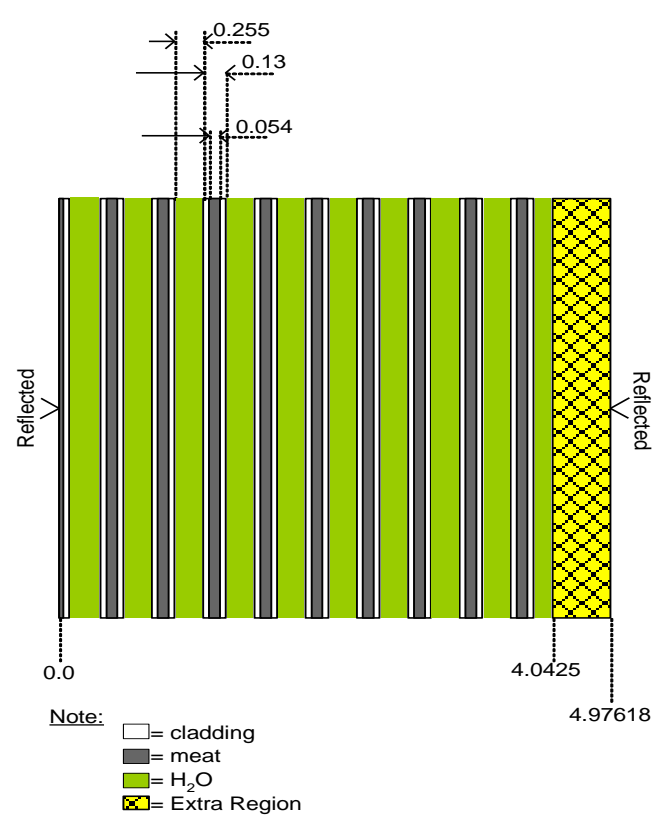

Fig. 4. Fuel element cell model (dimensions in $\mathrm{mm}$ ) [18].

\section{Control rod cell calculation}

Since the dimension of the active area (15 plates) in the control fuel element (Fig. 5) is the same as the standard one, the cross-sections of the standard fuel element can be used for this area. Figure 6 shows how to generate the fewgroup cross-sections for the Ag-In-Cd absorbers. This model is also applied for the other core materials.

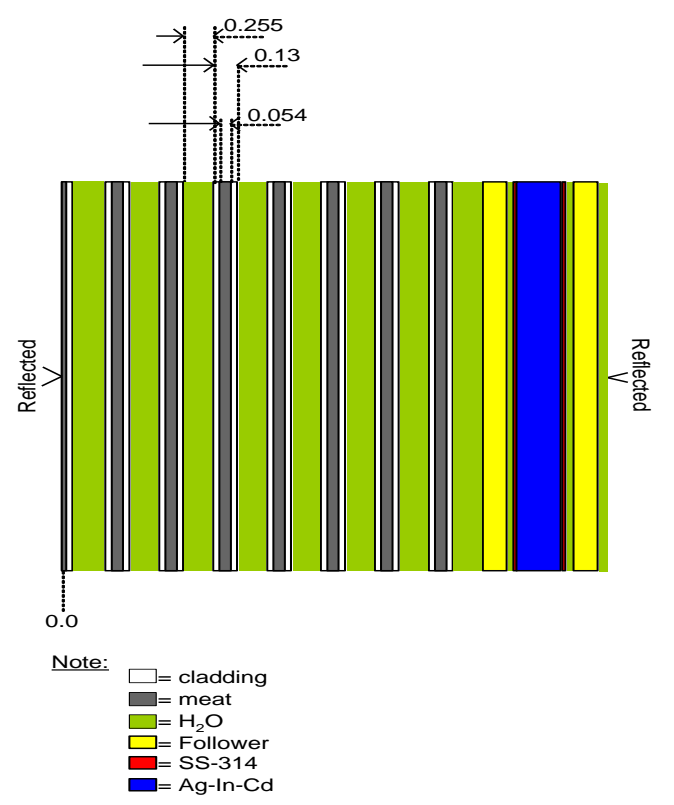

Fig. 6. Ag-In-Cd absorber cell model (size in $\mathrm{mm}$ ) [20].

\section{Core calculation model}

The neutronic parameters of the core were calculated by using the Batan-FUEL code [15].
The model is a two-dimensional $\mathrm{X}-\mathrm{Y}$ geometry model. To calculate the reactivity of control rod worth using Batan-3DIFF code one of the several modules in Batan-FUEL code. The few-group crosssection of each region was calculated beforehand, such regions are fuel element, control rod, and reflector regions, among others. Those crosssections were then applied to each region. Neutronics calculation methods and models for core calculation of RSG-GAS reactor are shown in Table 2.

Table 2. Neutronics calculation method [16].

\begin{tabular}{cc}
\hline Items & RSG-GAS \\
Nuclear Data File & $\begin{array}{c}\text { ENDFVII.0 (from } \\
\text { WIMSD-5B code) } \\
\text { Fuel Cell Calculation } \\
\text { Code }\end{array}$ \\
Theory & WIMSD-5B \\
Model & $\mathrm{S}_{\mathrm{N}}$ \\
Core Calculation Code & 1-D with multi plate \\
Theory & Batan-Equil-2D) \\
Model & Diffusion \\
No. of groups & 2-D, X-Y geometry \\
(Fast + Thermal) & 4 \\
\hline
\end{tabular}

Batan-FUEL can calculate many core parameters concerning reactor design. These parameters are excess reactivity, control rod worth, shutdown margin, reactivity coefficient, neutron flux distribution, power density distribution, and kinetic parameters (prompt neutron life time, prompt neutron generation time, delayed neutron fraction and delayed neutron decay constant).

Since the diffusion code is not accurate for calculations of the strong absorber region, Batan-FUEL applies extrapolation constant to the boundary of the black absorber [16]. The extrapolation constant is based on the Monte Carlo calculation result.

Batan-FUEL's primary application is for calculating criticality search of an equilibrium core without simulating the transition cores; therefore, the code is a core management code and performs core burnup calculations. These codes can calculate excess reactivity, shutdown margin, fuel burnup ratio, flux distribution, and power distribution at each operation cycle. Also, these codes can be applied for fuel exchange planning and fuel inventory management. Therefore, those capabilities strongly depend on the cell calculation. The calculation results will be compared to the experimental data. 


\section{Monte carlo calculation}

The active part $(7.71 \mathrm{~cm} \times 8.1 \mathrm{~cm} \times 60 \mathrm{~cm})$ of both standard and control fuel elements were modeled as their exact geometries and dimensions. However the top and end-fitting of the elements were modeled in an approximate manner since their geometries are very complicated; the structure materials were homogenized with water by volume weighting. An exact modeling approach was also taken for the active parts of the beryllium reflector elements, beryllium block elements, and irradiation positions. Despite their complicated geometries, the core grid and bottom support were also treated, through approximations, as for the top or end-fitting of fuel elements. This approximation did not deteriorate the accuracy of the Monte Carlo calculation results since it was applied on the non-active parts of the core. The movable control rods (absorber blades) were modeled as their exact geometry and dimensions. Consequently, the 60-cm-thick water layer above the core had to be included in the calculation to provide enough space for the absorber blades when a control rod was fully withdrawn. Approximately $30 \mathrm{~cm}$ of water layer was included below the core bottom support and around the beryllium block and element reflectors. Vacuum boundary conditions were imposed on the outer boundary of the reactor system. All Monte Carlo calculations in the present work were conducted with libraries from ENDFVII.1 for the temperature of $300 \mathrm{~K}$. The measured critical effective multiplication factors were corrected when the core isothermal temperature was not $300 \mathrm{~K}$. The total number of particles simulated was 600.000 for all cases considered. The calculation results will be compared to the experimental data.

Based on the experience of control rod worth estimation using deterministic and stochatic codes [21], we have formulated the approach for the analysis of calculated results. Three parameters are analyzed: the spread of calculated reactivity for control rod calibration critical cases with different control rod positions (for the rod compensation method), the shape of the integral control rod worth curves, and the integral control rod worth.

The following criteria for the discrepancy between the calculated and measured results were established [22]: (1) The maximum difference between the calculated reactivity values (the spread of calculated reactivity) for control rod calibration critical cases with different control rod insertion depths should be less than 0.4 \$, (2) The difference between the calculated and measured integral control rod worth should be $10 \%$ or less, (3) The shape of the calculated and measured integral control rod worth curves should be practically the same. That is, the calculated and measured integral control rod worth curves in relative units should be very close.

\section{RESULT AND DISCUSSION}

There are six control rods in the first RSG-GAS core at locations of C-5, C-8, D4, E-9, F-5, and F-8 (see Fig. 2). Table 3 shows the comparison between experiment data and Batan3DIFF and MCNP6 calculation results for criticality and excess reactivity of RSG-GAS first core. The differences between calculation and experimental result for control rod worth and the excess reactivity are $10.73 \%$ and $4.18 \%$, respectively, for Batan-3DIFF using ENDF6.8 library data file, while for ENDF7.0 library data file the differences are $10.06 \%$ and $4.14 \%$, respectively. Table 3 also shows the comparison between experimental data and MCNP6 calculation results for criticality and excess reactivity of RSG-GAS first core. The difference between calculation and experimental result for control rod worth and the excess reactivity are $6.24 \%$ and $2.83 \%$, respectively. MCNP6 code overestimates compared with Batan-3DIFF code results. However, the Monte Carlo method provided a better result for calculation of total control rod worth for RSG-GAS first core, since the Monte Carlo code used the new library data file.

Table 3. Comparison of calculation results with experiment data of RSG-GAS first core.

\begin{tabular}{llllll}
\hline \multirow{2}{*}{ Core configuration } & & \multirow{2}{*}{ Exp. Data } & \multicolumn{2}{c}{ Batan-3DIFF } & MCNP6 \\
\cline { 4 - 6 } & & & ENDF6.8 & ENDF7.0 & ENDF7.1 \\
\hline Control rods all up & $\mathrm{K}_{\text {eff }}$ & 1.088642 & 1.084655 & 1.088333 & $1.085950 \pm 0.0008$ \\
$(12 \mathrm{FEs}, 6 \mathrm{CRs})$ & $\mathrm{C} / \mathrm{E}$ & & 0.996338 & 0.999716 & 0.997527 \\
Control rods all down & $\mathrm{K}_{\text {eff }}$ & \multirow{2}{*}{0.912312} & 0.925077 & 0.926736 & $0.913220 \pm 0.00008$ \\
$(12 \mathrm{FEs}, 6 \mathrm{CRs})$ & $\mathrm{C} / \mathrm{E}$ & & 1.013992 & 1.015810 & 1.000995 \\
Control rods worth & $\Delta \rho(\%)$ & \multirow{2}{*}{-17.8} & -15.89 & -16.01 & -18.91 \\
& $(\mathrm{C}-\mathrm{E}) / \mathrm{E}(\%)$ & & 10.73 & 10.06 & 6.24 \\
Excess reactivity & $\Delta \rho(\%)$ & \multirow{2}{*}{8.14} & 7.80 & 8.11 & 7.91 \\
& $(\mathrm{C}-\mathrm{E}) / \mathrm{E}(\%)$ & & 4.18 & 0.37 & 2.83 \\
\hline
\end{tabular}


Table 4 shows a comparison between Batan3DIFF calculation results with several critical conditions of RSG-GAS first core occurred during control rod calibration. This critical condition achieved when the calibrated rod was fully inserted and other rods were in a certain bank position. Calculation results showed good agreement with experimental results.

Table 4. Comparison of Batan-3DIFF code calculation results with experimental data obtained during control rod calibration experiments of RSG-GAS first core.

\begin{tabular}{|c|c|c|c|c|}
\hline \multirow{2}{*}{\multicolumn{2}{|c|}{$\begin{array}{l}\text { Calibrated rod/grid position } \\
\text { (calibrated rod } \\
\text { position/other rods bank } \\
\text { position) }\end{array}$}} & \multirow[t]{2}{*}{$\begin{array}{l}\text { Experiment } \\
\text { data }\end{array}$} & \multicolumn{2}{|c|}{$\begin{array}{c}\text { Batan-3DIFF Code } \\
\text { Calculation } \\
\end{array}$} \\
\hline & & & ENDF6.8 & ENDF7.0 \\
\hline \multirow{2}{*}{$\begin{array}{l}\text { JDA06/C-8 } \\
(600 \mathrm{~mm}, 310 \mathrm{~mm})\end{array}$} & $\mathrm{k}_{\mathrm{eff}}$ & 1.0 & 0.988156 & 0.998281 \\
\hline & $\mathrm{C} / \mathrm{E}$ & & 0.988077 & 0.998201 \\
\hline \multirow{2}{*}{$\begin{array}{l}\text { JDA01/ E-9 } \\
(600 \mathrm{~mm}, 316 \mathrm{~mm})\end{array}$} & $\mathrm{k}_{\mathrm{eff}}$ & 1.0 & 0.996062 & 0.997653 \\
\hline & $\mathrm{C} / \mathrm{E}$ & & 0.995982 & 0.997573 \\
\hline \multirow{2}{*}{$\begin{array}{l}\text { JDA03/ F-8 } \\
(600 \mathrm{~mm}, 307 \mathrm{~mm}\end{array}$} & $\mathrm{k}_{\mathrm{eff}}$ & 1.0 & 0.995535 & 1.000148 \\
\hline & $\mathrm{C} / \mathrm{E}$ & & 0.99545 & 1.000068 \\
\hline \multirow{2}{*}{$\begin{array}{l}\text { JDA05/ C-5 } \\
(600 \mathrm{~mm}, 312 \mathrm{~mm}\end{array}$} & $\mathrm{k}_{\mathrm{eff}}$ & 1.0 & 0.997942 & 0.998819 \\
\hline & $\mathrm{C} / \mathrm{E}$ & & 0.997862 & 0.998739 \\
\hline \multirow{2}{*}{$\begin{array}{l}\text { JDA04/ F-5 } \\
(600 \mathrm{~mm}, 310 \mathrm{~mm}\end{array}$} & $\mathrm{k}_{\mathrm{eff}}$ & 1.0 & 0.997672 & 0.999920 \\
\hline & $\mathrm{C} / \mathrm{E}$ & & 0.997592 & 0.999840 \\
\hline \multirow{2}{*}{$\begin{array}{l}\text { JDA07/ D-4 } \\
(600 \mathrm{~mm}, 318 \mathrm{~mm}\end{array}$} & $\mathrm{k}_{\mathrm{eff}}$ & 1.0 & 0.995881 & 0.998034 \\
\hline & $\mathrm{C} / \mathrm{E}$ & & 0.995801 & 0.997954 \\
\hline
\end{tabular}

\section{Integral and differential control rods reactivity curves}

Using the perturbation theory methodology in Batan-3DIFF code, the data from Table 1 was used to construct an integral reactivity worth curve for the RSG-GAS first core control rods. The results obtained from the perturbation fit to the rod compensation measurements (experiment-1) and bank compensation measurements (experiment-2) are found in Figs. 7(a)-7(f) along with an MCNP6calculated integral worth curve.

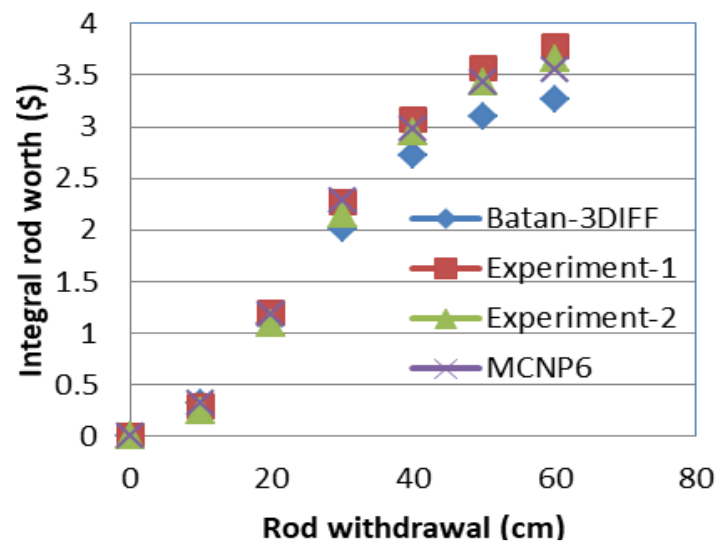

Fig. 7(a). Integral rod worth at C-5.

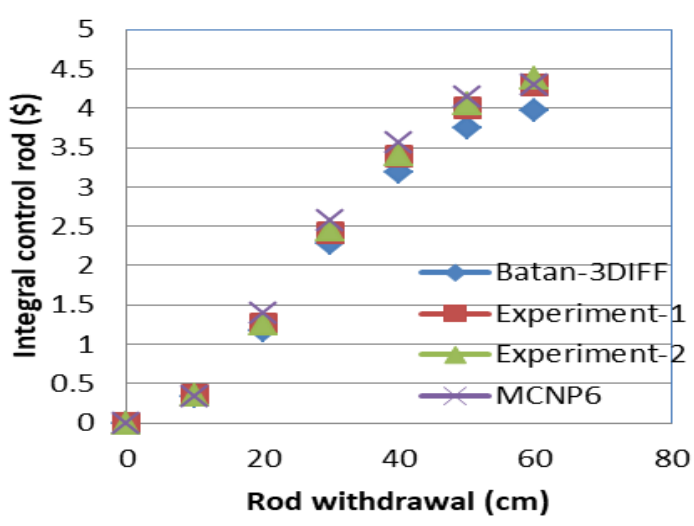

Fig. 7(b). Integral rod worth at C-8.

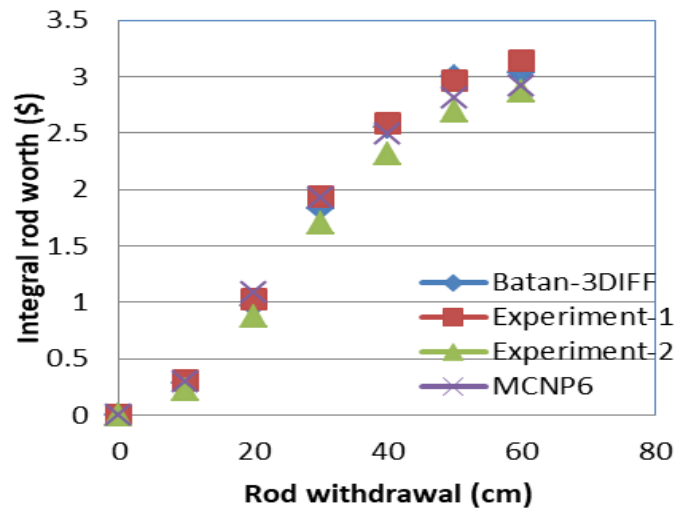

Fig. 7(c). Integral rod worth at D-4.

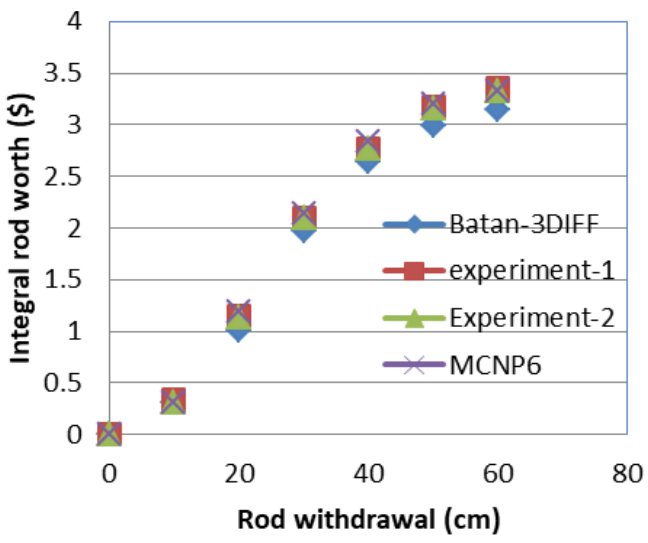

Fig. 7(d). Integral rod worth at E-9.

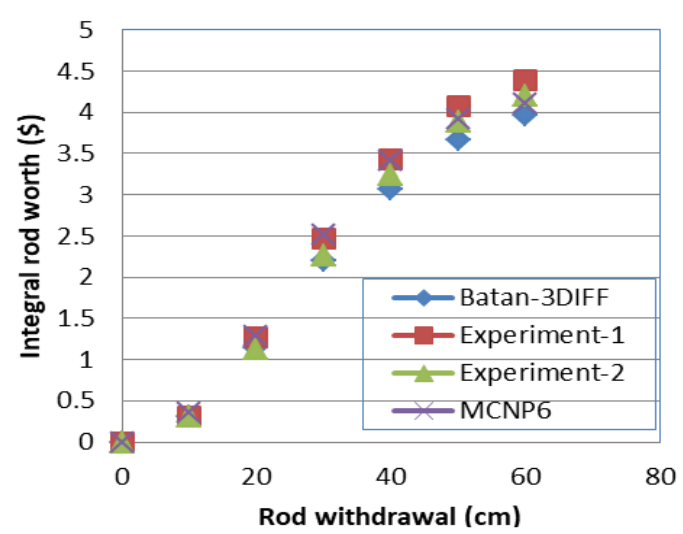

Fig. 7(e). Integral rod worth at F-5. 


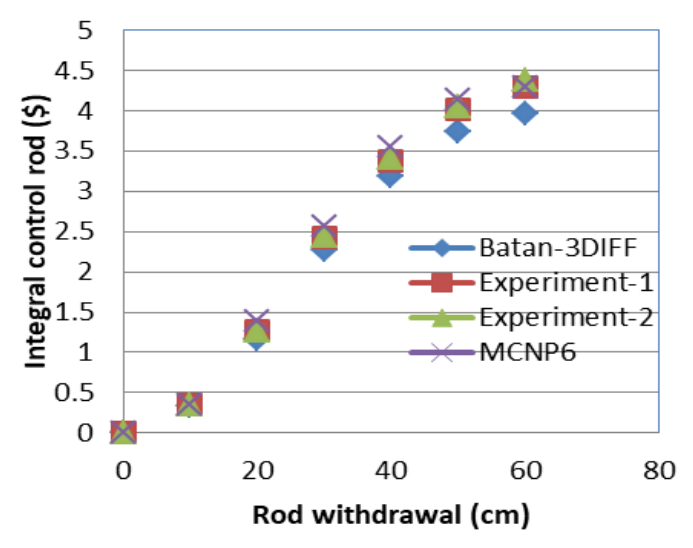

Fig. 7(f). Integral rod worth at F-8.

The MCNP6 curve was constructed by calculating the reactivity derived from $\mathrm{k}_{\text {eff }}$ values at incremental locations for the control rod bank. The $\mathrm{k}_{\text {eff }}$ calculations for the MCNP6 curve were performed using a previously described model of the first RSGGAS core. There is a close agreement between the integrals of the MCNP6 calculated curve, the perturbation method, and experiments result. The difference between data of experiment- 1 and perturbation method (Batan-FUEL) results is $9.6 \%$, whereas between the experiment-2 data and perturbation method results, the difference is $7.7 \%$ over the entire curve. From the comparison of the MCNP6 result to the data of experiment-1, the difference is $4.1 \%$, while compared to the data of experiment-2, the difference is $2.1 \%$. The high level of quantitative and qualitative agreement in addition to the lack of the ability to obtain positive period measurements for control rod bank positions between 0 and 60 rod units were the foundation for the recommendation that the curve derived from the MCNP6 calculations be implemented as the control rod bank integral reactivity worth curve for the first RSG-GAS core. Figures 7(a)-7(f) shows the curves for RSG-GAS control rods. The difference between the calculated and measured integral worth for the curves is less than $10 \%$. It meets the second criteria for analysis of integral control rod worth for RSG-GAS first core. In addition, there are two main sources of the discrepancy between the calculated and measured reactivity worth of control rod calibrated by the rod or bank compensation method: the experimental error in one control rod worth, which is used as a pattern, and inaccuracy of the control rod positioning (the absorber does not exactly align with the top and the bottom boundaries of the fuel meat in fully withdrawn and fully inserted positions). Fulfillment of the first and the third criteria depends on the knowledge of the control rod positioning and does not depend on the experimental error in control rod worth. The third criterion allows for examination of the positioning of individual CR, and for the fulfillment of the first criterion that the error in the positioning of all control rods should be less than $\pm 5 \mathrm{~cm}$. Fulfillment of the second criterion depends on the experimental error in control rod worth and practically does not depend on the knowledge of control rod positioning. Meeting all three criteria shows that the agreement between the calculation and the experiment in control rod reactivity worth is satisfactory.

Further, we present two results of the described methodology implementation on experiment for control rod calibration analysis for the RSG-GAS first core. Figures 7(a)-7(f) present the measured and calculated integral control rod worth curves in relative units for RSG-GAS first core. The results of six control rod calibrations carried out for rod and bank compensation methods are shown. The shape of the measured integral control rod worth curves obtained from calculations do not vary significantly between rods. The shapes of the curves for calibration control rods of C-5, C-8, D-4, E-9, F-5, and F-8 at position range of 0$40 \mathrm{~cm}$ are the same. At the position range of 40-60 $\mathrm{cm}$ the curves are different but their differences are still less than $0.5 \$$. The results of control rod calibrations for RSG-GAS first core show that the shape of the measured integral control rod worth curves is rather universal in the considered range of core with no depletion of the absorber; it almost does not depend on the fuel burnup distribution. The shape of the measured integral control rod worth curves depends mostly on the calibration procedure, that is, on control rod shadowing. Also, it can be seen in Fig. 7 that the difference between the different curves is in their central part only; for the control rod positions between 20 and $40 \mathrm{~cm}$, the curves in the middle of this range are very sensitive to the reactivity because in that area the neutron flux in the core is the highest and there is no difference between the shapes of the curves. For positions lower than $20 \mathrm{~cm}$ and higher than $40 \mathrm{~cm}$ the control rod is less sensitive because at those positions the neutron flux in the core is lower. The curves resulting from the two different measurements of relative integral worth were examined; the two measurement methods were calibration and direct measurement of control rod integral worth curves. They were compared with simulation results for control rod integral worth curves. The analysis shows that there is a good agreement between measurement and calculation results. Therefore, it can be concluded that the calculation results are reliable for the control rod reactivity worth of the first core of RSG-GAS for verification and validation of data and model.

The slope of the curve, and therefore the amount of reactivity inserted per unit of withdrawal, is greatest when the control rod is midway out of the core. This occurs because the area of greatest neutron flux is near the center of the core; therefore, the amount of change in neutron absorption is 
greatest in this area. If the slope of the curves for integral rod worth in Figs. 7(a)-7(f) are taken, the result is a value for rate of change of control rod worth as a function of control rod position. A plot of the slope of the integral rod worth curve, also called the differential control rod worth, are shown in Figs. 8(a)-8(f). At the bottom of the core, where there are few neutrons; therefore, rod movement has little effect $(0.2 \$ / \mathrm{cm})$ and the change in rod worth per $\mathrm{cm}$ varies little. As the rod approaches the center of the core its effect becomes greater, and the change in rod worth per $\mathrm{cm}$ is greater. At the center of the core the differential rod worth is greatest and varies little with rod motion. From the center of the core to the top, the rod worth per $\mathrm{cm}$ is basically the inverse of the rod worth per $\mathrm{cm}$ from the center to the bottom.

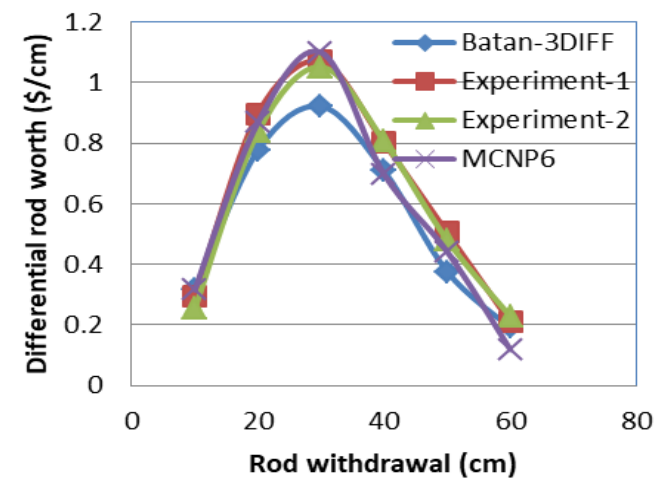

Fig. 8(a). Differential rod worth at C-5.

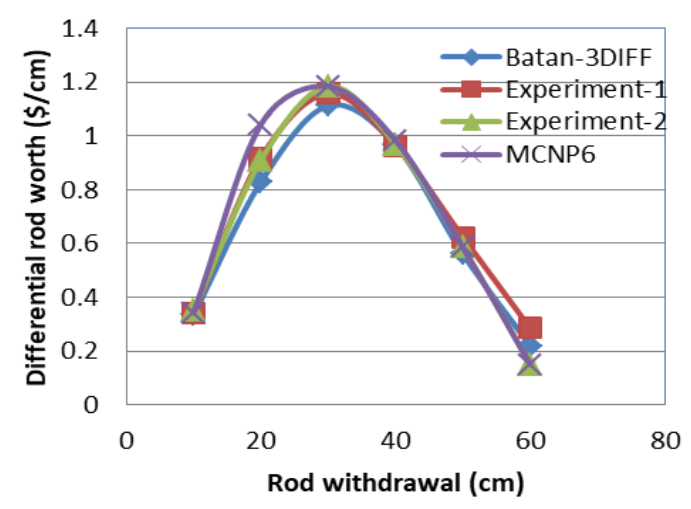

Fig. 8(b). Differential rod worth at C-8.

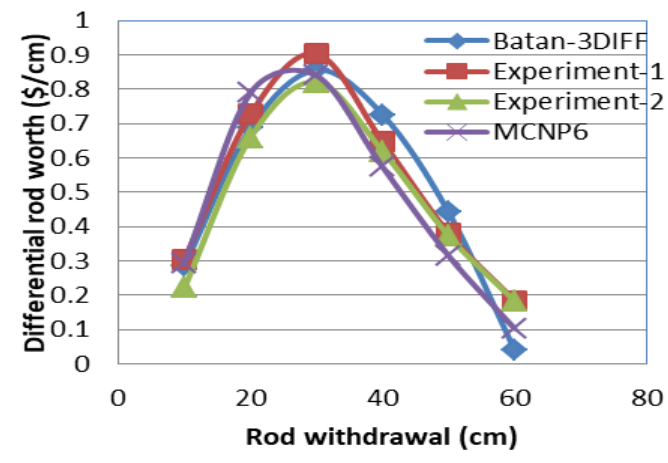

Fig. 8(c). Differential rod worth at D-4.

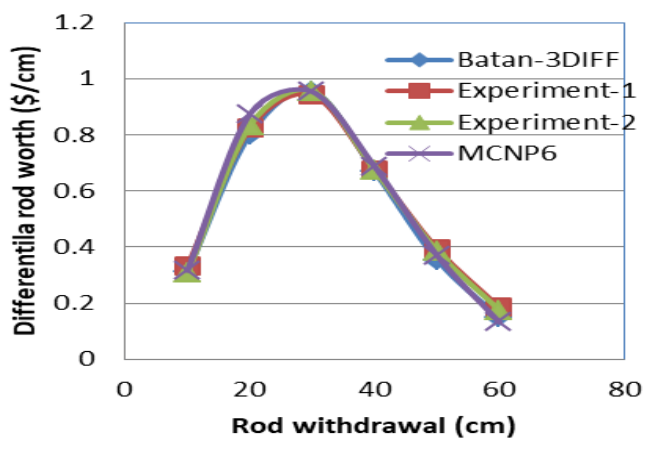

Fig. 8(d). Differential rod worth at E-9.

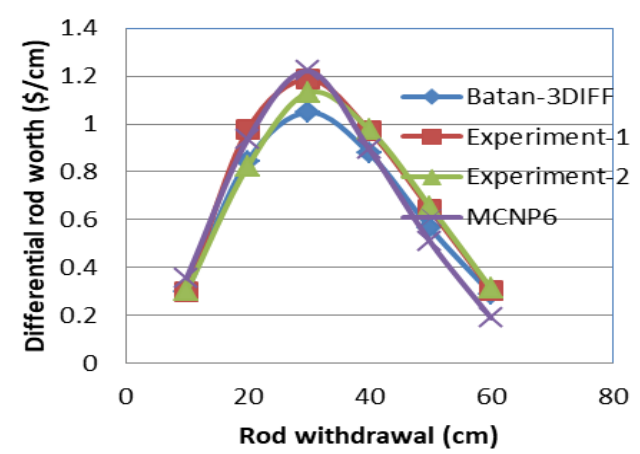

Fig. 8(e). Differential rod worth at F-5.

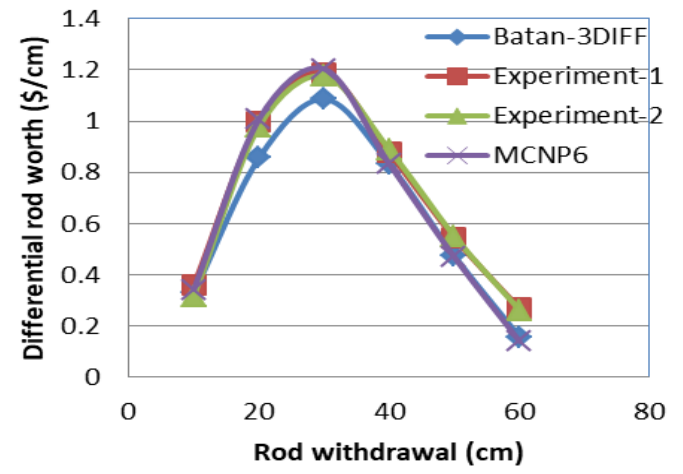

Fig. 8(f). Differential rod worth at F-8.

Differential worth curves for all four groups cross section are illustrated in Figs. 8(a)-8(f) for our calculations using deterministic and Monte Carlo results. Those figures include the measured values for RSG-GAS first core, and the results of Batan3DIFF can be considered good enough to be utilized for reactor operation, although the code gives smaller peak values and flatter differential curve shapes. Comparison are given in those figures for control rods C-5, C-8, D-4, E9, F-5, and F8 to illustrate our final optimized method (MCNP6) than the intermediate optimized results (Batan-3DIFF). The MCNP6 result is also given in the figure, which matches with our intermediate optimized methods. It is clear that intermediate optimized results are much flatter than the optimized results. It should be mentioned that all curves for all methods are 
calculated with same conditions under which the measurements have been performed, namely that there are six rods fixed at the height of $30 \mathrm{~cm}$ above the core bottom, the tested rod started from the completely inserted state, and the adjusting rod started from the completely withdrawn state. The accuracy of the reactivity obtained from the shape of the measured flux profile ultimately depends on the accuracy with which the kinetic parameters set are known.

The effectiveness, or worth, of a control rod depends largely upon the value of the neutron flux at the location of the rod. Figure 2 presents a top view of the RSG-GAS first core configuration, with six control rods consisting of the Regulating (C-5) and Shim (C-8, D-4, E-9, F-5, F-8) control rod positions. The experimental data obtained in the integral fitted worth curves of the Regulating, and Shim rods. Integral control rod worths as a function of their positions are shown graphically in Figs. 7(a)-7(f), respectively. The integral control rod worth curve is particularly important in research reactor operation. The measured values of the Regulating and Shim control rod worths are shown in Table 5. Comparison of the total reactivity of control rods in the group in Table 3 and total reactivity of control rods sum one by one in Table 5 show differences because of shadowing effect. Shadowing effect of RSG-GAS control rods has been analyzed by another researcher [23].

Table 5. Total control rods worth of RSG-GAS first core.

\begin{tabular}{llllll}
\hline No. & position & $\begin{array}{c}\text { Batan- } \\
\text { 3DIFF } \\
(\$)\end{array}$ & $\begin{array}{c}\text { Exp-1 } \\
(\$)\end{array}$ & $\begin{array}{c}\text { Exp-2 } \\
(\$)\end{array}$ & $\begin{array}{c}\text { MCNP6 } \\
(\$)\end{array}$ \\
\hline 1 & C-5 & 3.26 & 3.78 & 3.65 & 3.55 \\
2 & C-8 & 3.76 & 4.29 & 4.37 & 4.29 \\
3 & D-4 & 3.03 & 3.14 & 2.87 & 2.91 \\
4 & E-9 & 3.96 & 4.29 & 4.37 & 4.29 \\
5 & F-5 & 3.96 & 4.38 & 4.19 & 4.10 \\
6 & F-8 & 3.84 & 4.24 & 4.18 & 4.00 \\
Total control & 21.81 & 24.12 & 23.63 & 23.14 \\
rods worth (\$) & & & & \\
\hline
\end{tabular}

\section{CONCLUSION}

In the present work, a package based on computer codes WIMSD-5B and Batan-3DIFF has been applied for calculation of the control rods reactivity worth of the RSG-GAS first core. The differential and integral rods worth are obtained by a computer program that calculates the critical fresh fuel configuration. The results of this study are compared with the stochastic calculations using the MCNP6 code. The accuracy of obtained results from the proposed method is validated based on experimental data. However, they could be validated by two experimental measurements. The experimental method estimates the worth more accurately than WIMSD-5B/Batan-3DIFF and shows its capability to effectively and accurately calculate the reactor physics parameters. A series of experiments were performed to determine the integral reactivity worth curve for the first RSG-GAS core. The experiments were compared to both calculation results of the curves from MCNP6 and Batan-3DIFF codes. Comparison of results of the experiment series and MCNP6 calculations show a good agreement; however, comparison of the experimental results and Batan-3DIFF results show that the control rod reactivity worth curves exhibit a $10 \%$ difference. The comparison results show that the integral and differential reactivity worth which results from experiments exhibit a better agreement with the MCNP6 results; for that reason, that curve that is currently used by the RSG-GAS operations. Control rod worth is the main concern to ensure operational safety of the reactor. The maximum reactivity of the control rods which is obtained from the measurement and calculations exhibit a difference of about $5 \%$ in the worst case. The present reactivity of the control rods decreases from the previously measured reactivity of the control rods and it will decrease continuously in the future because of core burnup. The obtained differential curves are not exactly symmetrical about the midpoint of the rod and integral curve are not purely S-shaped. This is due to the neutron flux distribution in the RSG-GAS first core. From the analysis of these results obtained in this research it was concluded that the control rod worth is sufficient to shut down the reactor safely. These research results can be used as a reliable control rod worth of the first core of RSG-GAS for verification and validation.

\section{ACKNOWLEDGMENT}

The authors would like to thank the Head of PRSG and Operations Staff members for access to the reactor facility to perform the experiments and the fantastic training experience that it provided. In addition, the authors want to thank to Head of PTKRN and all researchers for their enthusiastic support and suggestions for this research project.

\section{REFERENCES}

1. E.K. Boafo, E. Alhassan, E.H.K. Akaho et al., Res. J. Appl. Sci. Eng. Technol. 5 (2013) 1129.

2. T. Surbakti, S. Pinem, T.M. Sembiring et al., Tri Dasa Mega 3 (2012) 179. (in Indonesian) 
3. I. Kuntoro and T.M. Sembiring, Tri Dasa Mega 16 (2014) 1. (in Indonesian)

4. T. Goorley, M. James, T. Booth et al., Ann. Nucl. Energy 87 (2016) 772. https://doi.org/10.1016/j.anucene.2015.02.020

5. H. Kazeminejad, Ann. Nucl. Energy 45 (2012) 59. http://dx.doi:10.1016/j.anucene.2012.02.017

6. F. Saadatian-derakhshandeh, O. Safarzadeh, and A.S. Shirani, Nukleonika 59 (2014) 67. http://dx.doi.10.2478/nuka-2014-0006

7. M.V. Shchurovskaya, V.P. Alferov, N.I. Geraskin et al., Ann. Nucl. Energy 96 (2016) 332.

http://dx.doi.org/10.1016/j.anucene.2016.06.015

8. N.A. Son, N.D. Hoa, T.T. Nguyen et al., World Journal of Nuclear Science and Technology 7 (2017) 15. http://dx.doi.org/10.4236/wjnst.2017.71002

9. G. Wang, J. Ma, S. Yuan et al., Ann. Nucl. Energy 85 (2015) 183.

http://dx.doi.org/10.1016/j.anucene.2015.05.005

10. I.D. Abdelrazek, M. Naguib Aly, A.A. Badawi et al., Ann. Nucl. Energy 70 (2014) 36. http://dx.doi.org/10.1016/j.anucene.2014.02.023

11. X. Shen, K. Nakajima, H. Unesaki et al., Ann. Nucl. Energy 62 (2013) 195. http://dx.doi.org/10.1016/j.anucene.2013.06.014.

12. M.A. Albatia, S.O. AL-Yahiaa, J. Park et al., Prog. Nucl. Energy 71 (2014) 1. http://dx.doi.org/10.1016/j.pnucene.2013.10.015

13. D. Jo, J. Park and H. Chae, Prog. Nucl. Energy 71 (2014) 39. http://dx.doi.org/10.1016/j.pnucene.2013.11.006

14. M.J.H. Khan, A.B.M.K. Alam, M.H. Ahsan et al., Ann. Nucl. Energy 85 (2015) 1014. https://doi.org/10.1016/j.anucene.2015.07.019

15. L.P. Hong, Atom Indonesia 22 (1996) 67.

16. T. Surbakti and T.M. Sembiring, Tri Dasa Mega 18 (2016) 29. (in Indonesian)

17. L. Suparlina and T. Surbakti, Tri Dasa Mega $\mathbf{1 6}$ (2014) 89. (in Indonesian)

18. S. Pinem, T.M. Sembiring and P.H. Liem, Atom Indonesia 42 (2016) 123. http://dx.doi.org/10.17146/aij.2016.532.

19. A. Hedayat, Prog. Nucl. Energy 71 (2014) 61. http://dx.doi.org/10.1016/S0149-1970(14) 00018-3

20. S. Pinem and I. Kuntoro, Journal of Nuclear Materials Technology 10 (2014) 1. (in Indonesian)

21. R. Nasira, M.K. Buttb, S.M. Mirzac et al., Ann. Nucl. Energy 85 (2015) 869. http://dx.doi.org/10.1016/j.anucene.2015. 07.003 .

22. H.J. Ryu and Y.S. Kim, Nucl. Eng. Technology 46 (2014) 159.

http://dx.doi.org/10.5516/NET.07.2014.705

23. T. Taryo, Atom Indonesia 27 (2001) 103. 